\title{
Comparative Study on the Performance of Health Workers in the Reduction of Patients Waiting Time in Public Hospitals in Yenagoa
}

\author{
Diri, G.E. ${ }^{1}$ and Eledo, B.O. ${ }^{1,2^{*}}$ \\ ${ }^{1}$ Federal Medical Centre, Yenagoa \\ ${ }^{2}$ Department of Medical Laboratory Science, Madonna University, Nigeria \\ *Corresponding Author: Eledo, B.O., Department of Medical Laboratory Science, Madonna University, \\ Nigeria
}

\begin{abstract}
The satisfaction of healthcare service received by patients is crucial to them and it is traceable to the reduction of their waiting time in the hospital. The outpatient department of any hospital is described as the gateway of the hospital as it is usually the first point of contact between the patients and the facility. It is therefore ensure that the healthcare/service providers are of good behaviour (politeness) and experience in delivering the expected services to the clients to prevent prolonged waiting. Therefore, reducing waiting time and making sure that patients are given the needed attention at the right time will have a significant impact on the quality of healthcare services patients received. Patients are attended to in various outpatients' units within the hospital at various times. Lengthy time is considered to be usually frustrating to the patients thereby making them to be totally dissatisfied with the services they received from the hospital. Thus, the study aimed at investigating and comparing the performance of health workers in delivering various services in the reduction of patients' waiting time in three major public hospitals in Yenagoa, Bayelsa state. The study used simple random sampling technique to examined 300 participants who were randomly drawn from the pool of patients of an infinite population, using patients' waiting time as a parameter to measure their performance. Out of the one hundred (100) questionnaires administered to each of the three hospitals, Sixty eight (68) questionnaires were filled and retrieved from FMC and NDTH while sixty six (66) were retrieved from DKMH. Frequency and simple percentage distribution methods of analyses were employed to analyze the data. Based on the standards set by the Patients Charter of the United Kingdom (UK), which states that all patients must be seen within 30minutes of their appointment time. Thus, the waiting time on this study was set within 30minutes to measure the performance of the health workers of the three major public hospitals in Bayelsa state. From the findings, the three hospitals were able to attend to their outpatients within 30minutes on the average of their appointment time. Though, the amount of time doctors spent in attending to their patients differed from the various hospitals; FMC and NDTH spent 30minutes - Thour. Therefore, FMC and NDTH doctors are fairly efficient. However, DKMH doctors spent 15-30minutes hence, they are more efficient. The cleanliness and comfort of the OPD from the findings, FMC was good but DKMH and NDTH were not too good or too bad. The receptionists for all the three hospitals were very good with their performance from the rating of the patients.
\end{abstract}

Keywords: Public Hospitals, Reduction of Patient's Waiting Time, Performance of Health Workers.

\section{INTRODUCTION}

The amount of time a patient waits to be seen by a doctor is one factor which affects the utilization of health care services especially in government hospitals. Patients' waiting time has emerged as an increasingly important parameter in the assessment of quality health care, hence health care facility performance can best be assessed by measuring patients' satisfaction which also depends on the reduction of patients' waiting time. It is difficult to sell services if individuals are not satisfied with the waiting time which is the length of time from when the patient entered the waiting room or the consulting room to the time the patient actually leaves the hospital (Markey and cole, 1997).

Waiting time has become a factor in relating with current users of the health facilities to assess the quality and performance of health care service providers as well as an index in measuring patients' satisfaction. A completely satisfied patient believes that the organization has the potential in understanding patient's needs and demand related to health care promptly (net et al, 2007).

It is a globally accepted fact that a well designed health system renders timely and convenient 
access to services for all patients. Patients waiting time for health care services are identified by six guiding principles to staying ahead in a more competitive health care delivery system. And it was put together by the United States institute of medicines report. One of these principles is the ability to provide care and reduce harmful delays. Again, the patients Charter of the United Kingdom (UK) sets a series of standards which stated that all patients must be seen within 30minutes of their appointment time. A strong inverse relationship between patients' satisfaction and waiting time has been demonstrated by many studies. The problem of outstanding waiting time in the global health system lies in two aspects: one is long waiting time at the registration and the admission window, and the other aspect of the problem is the long waiting time between the appointment time and the time patients are attended to by the doctors.

Usually, it is observed that patients at the hospital in the outpatients' department (OPD) have to wait for inexplicably long time before they can get medical treatment or advice by the professional health workers. Because of the volume of ambulant patients in most communities, an efficient outpatient department in most hospitals is clearly of critical importance. This is more because of the lower cost of outpatient services compared to in-patients, proximity of the hospital/ easy accessibility and perceived adequacy in manpower (doctors and nurses as well as other workers). The major problem faced by the hospital when it comes to running the OPD is the extended waiting periods and over-crowding (Anil et al, 2016). The waiting period is the most indicators of the quality of service. Thus, a prolonged waiting time directly reflects on the quality of service being provided. Patients' satisfaction should attract huge concern and usefulness as it provides the chance for the health care service providers and managers to improve the services in public health facilities which are one of the reasons why federal government introduced SERVICOM operation into the hospital system and it is still operational. Patients' feedback is necessary to identify problems that need to be resolved in improving the health care services. Hall et al (2006), stated that three goals that benefit from health care delay reduction are waiting time reduction for needed services, elimination of inefficient activities and the operational cost reduction. Anil et al (2018), concluded that information gathered during the study also revealed that $33 \%$ of patients waited for 30-60 minutes for the doctor while 32\% patients waited for over an hour. This was the major cause of discontent among the OPD patients to which a fall in OPD number can be attributed to.

\section{Employees' Performance}

Employees' performance refers to job related activities expected of a worker and how well those activities are executed. Employees' performance involves factors such as quality, quantity and effectiveness of work as well as the behaviours the employees show in the work environment. Employees' performance is simply measured or evaluated in different ways. These include:

- Level of execution

- Level of creativity

- Time management

- Quality of work

- Amount of consistency

- Revenue generated

- Ability to take ownership

To motivate workers to achieve adequate performance

- Create a friendly work environment

- Acknowledge employee's achievement

- Reward employees

- Positive communication is very important

\section{Statement of Problem}

Waiting time for healthcare services has been considered a serious problem in many healthcare systems since it is used as a yardstick to measure patients' satisfaction, managerial effectiveness and equity in providing healthcare services to customers. It is also considered as a measurable parameter for checking the efficiency of hospital and its professionals for improved service delivery. OPD is considered as the window to hospital services. Also, patients' impression of the hospital begins at the OPD. This impression often influences the patients' sensitivity to the hospital and therefore it is essential to ensure that OPD services are of excellent experience for patients. Thus, the researcher aimed at verifying the performance of health workers of the three major public 
Comparative Study on the Performance of Health Workers in the Reduction of Patients Waiting Time in Public Hospitals in Yenagoa

hospitals in Bayelsa state in relation to the reduction of patients' waiting time to measure their satisfaction.

\section{Objective of the Study}

The major objective of the study was to examine the performance of healthcare service providers using patients' waiting time in three public hospitals in Yenagoa, Bayelsa state.

The specific objectives were:

- To verify patients' perspectives about the effectiveness and the efficiency of healthcare service providers in relation to patients' waiting time reduction.

- To determine at what extent patients' are satisfied or dissatisfied with the nature of healthcare services they received

\section{Research Questions}

The following research questions would be answered

- To what extent are the healthcare service providers efficient and effective in relation to the reduction of the patients' waiting time?

- To what extent are the patients satisfied or dissatisfied with the nature of healthcare services they received?

\section{METHODOLOGY}

The study was a comparative descriptive survey design. The study used simple random sampling technique to examined 300 participants who were randomly drawn from the pool of patients of an infinite population of the three (3) public hospitals which rendered services to the people of Bayelsa state - both the rich and the poor, young and old. The three hospitals - Federal Medical Centre (FMC), Yenagoa, Diete Koki Memorial Hospital Opolo, Yenagoa and Niger
Delta University Teaching Hospital, Okolobiri all in Bayelsa state. Out of the three hospitals, two are located in the heart of the state Yenagoa (FMC and Diete Koki Memorial) hospitals and surrounded by primary health centres and private hospitals while the other is located in the out sketch of the state in the midst of various communities. The study used pre test questionnaires generated and validated by the researcher.

One hundred (100) questionnaires were administered to each of the hospital titled "Performance of Health Workers in the Reduction of Patients' Waiting Time in Public Hospitals in Yenagoa" for two weeks from Monday to Friday. The participants were informed about the research and its objectives. They were assured of their confidentiality during and after the study and information given were used only for the research purpose. The questionnaires were completed with the help of some assistant researchers -colleagues. Out of one hundred (100) questionnaires administered, Sixty eight (68) questionnaires were filled and retrieved from FMC and NDTH while sixty six (66) were retrieved from DKMH. Frequency and simple percentage distribution methods of analyses were employed to analyze the data. To ascertain the reliability of the instrument, the researcher employed test and retest approach.

\section{Data Analysis of Federal Medical Centre} Yenagoa, Bayelsa State

Out of the one hundred (100) questionnaires administered to the patients who came to receive various healthcare services at the hospital, sixty eight (68) were retrieved making 68 percent of the responses.

Demographics of the Respondents

Table1. Age of the Respondents

\begin{tabular}{|c|c|c|}
\hline Age & Frequency & Percentage (\%) \\
\hline $18-25$ & 9 & 13.2 \\
\hline $26-34$ & 16 & 23.5 \\
\hline $35-43$ & 24 & 35.3 \\
\hline $44-52$ & 12 & 17.6 \\
\hline 53 above & 7 & 10.3 \\
\hline Total & 68 & 100 \\
\hline
\end{tabular}

Out of the 68 responses $13.2 \%$ of them were within the age bracket of 18-25 with a frequency of 9; $23.5 \%$ were within the age bracket of 26-34 with a frequency of 16; $35.3 \%$ are within the age bracket of 35-43 with a frequency of $24 ; 17.6 \%$ were within the age bracket of 44-52 with a frequency of 12; $10.3 \%$ were within the age bracket of 53 and above with a frequency of 7 . The average age bracket which is the modal age was 35-43 with the highest frequency. 
Comparative Study on the Performance of Health Workers in the Reduction of Patients Waiting Time in Public Hospitals in Yenagoa

Table2. Gender of the Respondents

\begin{tabular}{|c|c|c|}
\hline Sex & Frequency & Percentage (\%) \\
\hline Male & 18 & 26.5 \\
\hline Female & 50 & 73.5 \\
\hline Total & 68 & 100 \\
\hline
\end{tabular}

Out of the 68 responses $26.5 \%$ of them were males with a frequency of 18; 73.5\% were females with a frequency 50 .

Table3. Occupation of the Respondents

\begin{tabular}{|c|c|c|}
\hline Occupation & Frequency & Percentage (\%) \\
\hline Farming & 2 & 2.9 \\
\hline Civil service & 27 & 39.7 \\
\hline Self employed & 31 & 45.6 \\
\hline Private sector & 1 & 1.5 \\
\hline Student & 7 & 10.3 \\
\hline Total & 68 & 100 \\
\hline
\end{tabular}

Out of 68 responses, $2.9 \%$ of them were farmers with a frequency of $2 ; 39.7 \%$ of them were civil servants with a frequency of 27; $45.6 \%$ of them were self employed with a frequency of $31 ; 1.5 \%$ of them were private workers with a frequency of 1; $10.3 \%$ of them were students with a frequency of 7 .

Table4. Location of the Respondents

\begin{tabular}{|c|c|c|}
\hline Location & Frequency & Percentage (\%) \\
\hline Yenagoa & 54 & 79.4 \\
\hline Suburb of Yenagoa & 14 & 20.6 \\
\hline Total & 68 & 100 \\
\hline
\end{tabular}

From the table above, $79.4 \%$ of the respondents reside in Yenagoa and the $20.6 \%$ reside at the suburb of Yenagoa.

Simple Percentage and Frequency Distribution on the Experiences of the Respondents who were Patients that Needed Various Health care services Interviewed in the hospital.

Table5. Did patients book appointment or make enquiry if the doctors they are coming to see are on sit or around?

\begin{tabular}{|c|c|c|}
\hline Item & Frequency & Percentage (\%) \\
\hline Yes & 24 & 35.3 \\
\hline No & 44 & 64.7 \\
\hline Total & 68 & 100 \\
\hline
\end{tabular}

From the table above, $35.3 \%$ of the patients who came to see their doctors did book appointment with their doctors before coming while $64.7 \%$ did not.

Table6. Showing the rating of the receptionist as regards to how the patients were attended to

\begin{tabular}{|c|c|c|}
\hline Item & Frequency & Percentage \\
\hline Very satisfied & 16 & 23.5 \\
\hline Very good & 27 & 39.7 \\
\hline Good & 23 & 33.8 \\
\hline Average & 1 & 1.5 \\
\hline Poor & 1 & 1.5 \\
\hline Very Poor & - & 100 \\
\hline Total & 68 & - \\
\hline
\end{tabular}

The table above showed that, $23.5 \%$ of the patients felt very satisfied with the way the receptionist attended to them with a frequency of 16; 39.7\% felt very good with the way they were attended to by the receptionist with a frequency of 27; 33.8\% felt good. The average rating was very good which the mode with the frequency of 27. This means that the receptionist attended to the patients well.

Table7. Showed the length of waiting time patients spent to meet their doctors after arrival

\begin{tabular}{|c|c|c|}
\hline Item & Frequency & Percentage (\%) \\
\hline Less than 15minutes & 6 & 8.8 \\
\hline 15-30minutes & 29 & 42.6 \\
\hline 30-1hour & 11 & 16.2 \\
\hline 1hour and above & 22 & 32.4 \\
\hline Total & 68 & 100 \\
\hline
\end{tabular}


Comparative Study on the Performance of Health Workers in the Reduction of Patients Waiting Time in Public Hospitals in Yenagoa

From the table above, $8.8 \%$ of the patients said, the waiting time to meet with their doctors after they arrived the hospital with a frequency of 6 was less than 15minutes; $42.6 \%$ said they spent 15-30minutes before meeting with their doctors with a frequency of 29; 16.2\% spent 30-1hour and 32.4 said they waited for 1hour and above before meeting with their doctors. The average waiting time was 15-30minutes with the highest frequency of 29.

Table8. Showing the length of time taken by the doctors to attend to their patients

\begin{tabular}{|c|c|c|}
\hline Item & Frequency & Percentage (\%) \\
\hline 15-30minutes & 11 & 16.2 \\
\hline 30-1hour & 30 & 44.1 \\
\hline 1hour and above & 27 & 39.7 \\
\hline Total & 68 & 100 \\
\hline
\end{tabular}

The table showed that, 16.2\% said their doctors spent 15-30minutes attending to each patient with a frequency of 11; 44.1\% said their doctors spent 30-1hour attending to each patient with a frequency of 30 while $39.7 \%$ with a frequency of 27 said, their doctors spent lhour and above attending to them. Hence, the average time taken by doctors attending to each patient was 30-1hour with the highest frequency of 30.

Table9. Showing the rate of satisfaction by patients meeting with their doctors

\begin{tabular}{|c|c|c|}
\hline Item & Frequency & Percentage (\%) \\
\hline Very satisfied & 12 & 17.6 \\
\hline Satisfied & 10 & 14.7 \\
\hline Very good & 28 & 41.2 \\
\hline Good & 11 & 16.2 \\
\hline Average & 7 & 10.3 \\
\hline Total & 68 & 100 \\
\hline
\end{tabular}

The table above showed that, $17.6 \%$ felt very satisfied with the way their doctors attended to them, $14.7 \%$ felt satisfied with the way their doctors attended to them, $41.2 \%$ felt very good with the way their doctors attended to them, $16.2 \%$ felt good while 10.3 felt averaged. Thus, the average satisfaction patients got from their doctors was very good with the highest frequency of 28.

Table10. Showing the overall level of satisfaction with the way patients were attended to.

\begin{tabular}{|c|c|c|}
\hline Item & Frequency & Percentage (\%) \\
\hline Satisfied & 40 & 58.8 \\
\hline Average & 1 & 1.5 \\
\hline Not satisfied & 25 & 36.8 \\
\hline Applicable & 2 & 2.9 \\
\hline Total & 68 & 100 \\
\hline
\end{tabular}

From the table above, $58.8 \%$ of the patients said they were satisfied with the way they were attended at the hospital FMC Yenagoa with a frequency of 40; 36.8\% said they were not satisfied at all with the way they were attended with a frequency of 25. Thus, the average level of total satisfaction of the patients was that they were satisfied which is the mode with the highest frequency of 40.

Table11. Showing the rating of the cleanliness and the comfort of the Outpatients Department (OPD) of the Hospital (FMC-Yenagoa)

\begin{tabular}{|c|c|c|}
\hline Item & Frequency & Percentage (\%) \\
\hline Very poor (1) & 11 & 16.2 \\
\hline Poor (2) & 12 & 17.6 \\
\hline Fair (3) & 12 & 17.6 \\
\hline Good (4) & 21 & 30.9 \\
\hline Very good (5) & 12 & 17.6 \\
\hline Total & 68 & 100 \\
\hline
\end{tabular}

Based on the rating of the cleanliness and comfort of the OPD of FMC-Yenagoa by the outpatients, the average rating with the highest frequency was good with 30.9\%. Meaning that, the cleanliness and comfort of OPD of the hospital from the assessment of the outpatients was good.

\section{Data Analysis of Diete Koki Memorial Hospital, Opolo, Yenagoa, Bayelsa State}

Out of the one hundred (100) questionnaires administered to the patients of the hospital, sixty six (66) were retrieved making 66 percent of the responses. 
Comparative Study on the Performance of Health Workers in the Reduction of Patients Waiting Time in Public Hospitals in Yenagoa

Demographics of the Respondents

Table1. Age of the Respondents

\begin{tabular}{|c|c|c|}
\hline Age & Frequency & Percentage (\%) \\
\hline $18-25$ & 32 & 48.5 \\
\hline $26-34$ & 15 & 22.7 \\
\hline $35-43$ & 6 & 9.1 \\
\hline $44-52$ & 7 & 10.6 \\
\hline 53 above & 6 & 9.1 \\
\hline Total & 66 & 100 \\
\hline
\end{tabular}

Out of the 66 responses $48.5 \%$ of them were within the age bracket of $18-25$ with a frequency of $32 ; 22.7 \%$ were within the age bracket of 26-34 with a frequency of 15; 9.1\% are within the age bracket of 35-43 with a frequency of 6; 10.6\% were within the age bracket of 44-52 with a frequency of 7; 9.1\% were within the age bracket of 53 and above with a frequency of 6 . The average age bracket which is the modal age bracket was 18 25 with the highest frequency of 32.

Table2. Gender of the Respondents

\begin{tabular}{|c|c|c|}
\hline Sex & Frequency & Percentage (\%) \\
\hline Male & 25 & 37.9 \\
\hline Female & 41 & 62.1 \\
\hline Total & 66 & 100 \\
\hline
\end{tabular}

Out of the 66 responses $37.9 \%$ of them were males with a frequency of 25; $62.1 \%$ were females with a frequency 41 .

Table3. Occupation of the Respondents

\begin{tabular}{|c|c|c|}
\hline Occupation & Frequency & Percentage (\%) \\
\hline Farming & - & - \\
\hline Civil service & 17 & 25.8 \\
\hline Self employed & 23 & 34.8 \\
\hline Private sector & 3 & 4.5 \\
\hline Student & 23 & 34.8 \\
\hline Total & 66 & 100 \\
\hline
\end{tabular}

Out of 66 responses, $25.8 \%$ of them were civil servants with a frequency of 17; $34.8 \%$ of them were self employed with a frequency of 23; $4.5 \%$ of them were private workers with a frequency of 3; $34.8 \%$ of them were students with a frequency of 23.

Table4. Location of the Respondents

\begin{tabular}{|c|c|c|}
\hline Location & Frequency & Percentage (\%) \\
\hline Yenagoa & 66 & 100 \\
\hline Suburb of Yenagoa & - & - \\
\hline Total & 66 & 100 \\
\hline
\end{tabular}

From the table above, $100 \%$ of the respondents reside in Yenagoa with a frequency of 66

Simple Percentage and Frequency Distribution on the Experiences of the Respondents who were Patients that Needed Various Health care services in the hospital

Table5. Did patients book appointment or make enquiry if the doctors they are coming to see are on sit or around?

\begin{tabular}{|c|c|c|}
\hline Item & Frequency & Percentage (\%) \\
\hline Yes & 34 & 51.5 \\
\hline No & 32 & 48.5 \\
\hline Total & 66 & 100 \\
\hline
\end{tabular}

From the table above, $51.5 \%$ of the patients who came to see their doctors did book appointment with their doctors before coming while $48.5 \%$ did not.

Table6. Showing the rating of the receptionist as regards to how the patients were attended to

\begin{tabular}{|c|c|c|}
\hline Item & Frequency & Percentage \\
\hline Very satisfied & 10 & 15.2 \\
\hline Very good & 26 & 39.4 \\
\hline Good & 16 & 24.2 \\
\hline Average & 10 & 15.2 \\
\hline Poor & 3 & 4.5 \\
\hline Very Poor & 1 & 1.5 \\
\hline Total & 66 & 100 \\
\hline
\end{tabular}


Comparative Study on the Performance of Health Workers in the Reduction of Patients Waiting Time in Public Hospitals in Yenagoa

The table above showed that, $15.2 \%$ of the patients felt very satisfied with the way the receptionist attended to them with a frequency of 10; 39.4\% felt very good with the way they were attended to by the receptionist with a frequency of 26; $24.2 \%$ felt good. The average rating was very good which the mode with the highest frequency of 26 is. This means that the receptionist attended to the patients well.

Table7. Showed the length of waiting time patients spent to meet their doctors after arrival

\begin{tabular}{|c|c|c|}
\hline Item & Frequency & Percentage (\%) \\
\hline Less than 15minutes & 18 & 27.3 \\
\hline 15-30minutes & 29 & 43.9 \\
\hline 30-1hour & 13 & 19.7 \\
\hline 1hour and above & 6 & 9.1 \\
\hline Total & 66 & 100 \\
\hline
\end{tabular}

From the table above, $27.3 \%$ of the patients said, the waiting time to meet with their doctors after they arrived the hospital was less than 15minutes with a frequency of 18; 43.9\% said they spent 15-30minutes before meeting with their doctors with a frequency of 29; 19.7\% spent 30-1hour and 9.1\% said they waited for 1hour and above before meeting with their doctors. Thus, the average waiting time was 15-30minutes with the highest frequency of 29.

Table8. Showing the length of time taken by the doctors to attend to their patients

\begin{tabular}{|l|l|l|}
\hline Item & Frequency & Percentage (\%) \\
\hline $15-30$ minutes & 36 & 54.5 \\
\hline $30-1$ hour & 23 & 34.8 \\
\hline 1hour and above & 7 & 10.6 \\
\hline Total & 66 & 100 \\
\hline
\end{tabular}

The table showed that, $54.5 \%$ said their doctors spent 15-30minutes attending to each patient with a frequency of 36; 34.8\% said their doctors spent 30-1hour attending to each patient with a frequency of 23 while $10.6 \%$ with a frequency of 7 said, their doctors spent lhour and above attending to each of them. Hence, the average time taken by doctors attending to each patient was 15-30minutes with a highest frequency of 36.

Table9. Showing the rate of satisfaction by patients meeting with their doctors

\begin{tabular}{|c|c|c|}
\hline Item & Frequency & Percentage (\%) \\
\hline Very satisfied & 22 & 33.3 \\
\hline Satisfied & 8 & 12.1 \\
\hline Very good & 15 & 22.7 \\
\hline Good & 13 & 19.7 \\
\hline Average & 8 & 12.1 \\
\hline Total & 66 & 100 \\
\hline
\end{tabular}

The table above showed that, 33.3\% felt very satisfied with the way their doctors attended to them, $12.1 \%$ felt satisfied with the way their doctors attended to them, $22.7 \%$ felt very good with the way their doctors attended to them, $19.7 \%$ felt good while felt averaged. Thus, the average satisfaction patients got from their doctors was very satisfied with the highest frequency of 22.

Table10. Showing the overall level of satisfaction with the way patients were attended to.

\begin{tabular}{|c|c|c|}
\hline Item & Frequency & Percentage (\%) \\
\hline Satisfied & 34 & 51.5 \\
\hline Average & - & - \\
\hline Not satisfied & 29 & 43.9 \\
\hline Applicable & 3 & 4.5 \\
\hline Total & 66 & 100 \\
\hline
\end{tabular}

From the table above, $51.5 \%$ of the patients said they were satisfied with the way they were attended at the hospital - Diete Koki Memorial with a frequency of 34; 43.9\% said they were not satisfied at all with the way they were attended with a frequency of 29. Thus, the average level of total satisfaction of the patients was that, they were satisfied with the highest frequency of 34.

Table11. Showing the rating of the cleanliness and the comfort of the Outpatients Department (OPD) of the Hospital (DKMH-Yenagoa)

\begin{tabular}{|c|c|c|}
\hline Item & Frequency & Percentage (\%) \\
\hline Very poor (1) & 3 & 4.5 \\
\hline Poor (2) & 6 & 9.1 \\
\hline Fair (3) & 26 & 39.4 \\
\hline Good (4) & 22 & 33.3 \\
\hline Very good (5) & 9 & 13.6 \\
\hline Total & 66 & 100 \\
\hline
\end{tabular}


Comparative Study on the Performance of Health Workers in the Reduction of Patients Waiting Time in Public Hospitals in Yenagoa

Based on the rating of the cleanliness and comfort of the OPD of DKMH -Yenagoa by the outpatients, the average rating with the highest frequency was fair with 39.4\%. Meaning that, the cleanliness and comfort of $O P D$ of the hospital from the assessment of the outpatients was not too good or too bad.

\section{Data Analysis of Niger Delta University Teaching Hospital, Okolobiri, Bayelsa State}

Out of the one hundred (100) questionnaires administered to the patients of the hospital, sixty eight (68) were retrieved making 68 percent of the responses.

Demographics of the Respondents

Table1. Age of the Respondents

\begin{tabular}{|c|c|c|}
\hline Age & Frequency & Percentage (\%) \\
\hline $18-25$ & 7 & 10.3 \\
\hline $26-34$ & 17 & 25.0 \\
\hline $35-43$ & 24 & 35.3 \\
\hline $44-52$ & 16 & 23.5 \\
\hline 53 above & 4 & 5.9 \\
\hline Total & 68 & 100 \\
\hline
\end{tabular}

Out of the 68 responses $10.3 \%$ of them were within the age bracket of 18-25 with a frequency of 7; 25.0\% were within the age bracket of 26-34 with a frequency of 17; 35.3\% were within the age bracket of 35-43 with a frequency of 24; $23.5 \%$ were within the age bracket of 44-52 with a frequency of 16; $5.9 \%$ were within the age bracket of 53 and above with a frequency of 4 . The average age bracket which is the modal age bracket was 35 43 with the highest frequency of 24.

Table2. Gender of the Respondents

\begin{tabular}{|c|c|c|}
\hline Sex & Frequency & Percentage (\%) \\
\hline Male & 38 & 55.9 \\
\hline Female & 30 & 44.1 \\
\hline Total & 68 & 100 \\
\hline
\end{tabular}

Out of the 68 responses $55.9 \%$ of them were males with a frequency of 38; $44.1 \%$ were females with a frequency 30.

Table3. Occupation of the Respondents

\begin{tabular}{|c|c|c|}
\hline Occupation & Frequency & Percentage (\%) \\
\hline Farming & 2 & 2.9 \\
\hline Civil service & 18 & 26.5 \\
\hline Self employed & 38 & 55.9 \\
\hline Private sector & - & - \\
\hline Student & 10 & 14.7 \\
\hline Total & 68 & 100 \\
\hline
\end{tabular}

Out of 68 responses, $2.9 \%$ of them were farmers with a frequency of 2; $26.5 \%$ of them were civil servants with a frequency of 18; $55.9 \%$ of them were self employed with a frequency of 38; $14.7 \%$ of them were students with a frequency of 10 .

Table4. Location of the Respondents

\begin{tabular}{|c|c|c|}
\hline Location & Frequency & Percentage (\%) \\
\hline Yenagoa & 36 & 52.9 \\
\hline Suburb of Yenagoa & 32 & 47.1 \\
\hline Total & 68 & 100 \\
\hline
\end{tabular}

From the table above, $52.9 \%$ of the respondents reside in Yenagoa while $47.1 \%$ reside at the suburb of Yenagoa.

Simple Percentage and Frequency Distribution on the Experiences of the Respondents who were Patients that Needed Various Health care services in the hospital

Table5. Did patients book appointment or make enquiry if the doctors they are coming to see are on sit or around?

\begin{tabular}{|c|c|c|}
\hline Item & Frequency & Percentage (\%) \\
\hline Yes & 27 & 39.7 \\
\hline No & 41 & 60.3 \\
\hline Total & 68 & 100 \\
\hline
\end{tabular}


Comparative Study on the Performance of Health Workers in the Reduction of Patients Waiting Time in Public Hospitals in Yenagoa

From the table above, $39.7 \%$ of the patients who came to see their doctors did book appointment with their doctors before coming while $60.3 \%$ did not.

Table6. Showing the rating of the receptionist as regards to how the patients were attended to

\begin{tabular}{|c|c|c|}
\hline Item & Frequency & Percentage \\
\hline Very satisfied & 10 & 14.7 \\
\hline Very good & 24 & 35.3 \\
\hline Good & 21 & 30.9 \\
\hline Average & 11 & 16.2 \\
\hline Poor & 2 & 2.9 \\
\hline Very Poor & - & - \\
\hline Total & 68 & 100 \\
\hline
\end{tabular}

The table above showed that, $14.7 \%$ of the patients felt very satisfied with the way the receptionist attended to them with a frequency of 10; 35.3\% felt very good with the way they were attended to by the receptionist with a frequency of 24; $30.9 \%$ felt good. The average rating was very good which the mode with the highest frequency of 24. This means that the receptionist attended to the patients well.

Table7. Showed the length of waiting time patients spent to meet their doctors after arrival

\begin{tabular}{|c|c|c|}
\hline Item & Frequency & Percentage (\%) \\
\hline Less than 15minutes & 17 & 25.0 \\
\hline 15-30minutes & 28 & 41.2 \\
\hline 30-1hour & 12 & 17.6 \\
\hline 1hour and above & 11 & 16.2 \\
\hline Total & 68 & 100 \\
\hline
\end{tabular}

From the table above, $25.0 \%$ of the patients said, the waiting time to meet with their doctors after they arrived the hospital was less than 15minutes with a frequency of 17; 41.2\% said they spent 15-30minutes before meeting with their doctors with a frequency of 28; 17.6\% spent 30-1hour and 16.2\% said they waited for 1hour and above before meeting with their doctors. Thus, the average waiting time was 15-30minutes with the highest frequency of 28 .

Table8. Showing the length of time taken by the doctors to attend to their patients

\begin{tabular}{|c|c|c|}
\hline Item & Frequency & Percentage (\%) \\
\hline 15-30minutes & 26 & 38.2 \\
\hline 30-1hour & 31 & 45.6 \\
\hline 1hour and above & 11 & 16.2 \\
\hline Total & 66 & 100 \\
\hline
\end{tabular}

The table showed that, 38.2\% said their doctors spent 15-30minutes attending to each patient with a frequency of 26; 45.6\% said their doctors spent 30-1hour attending to each patient with a frequency of 31 while $16.2 \%$ with a frequency of 11 said, their doctors spent 1 hour and above attending to each of them. Hence, the average time taken by doctors attending to each patient was 30minutes -1hour with a highest frequency of 31 .

Table9. Showing the rate of satisfaction by patients meeting with their doctors

\begin{tabular}{|c|c|c|}
\hline Item & Frequency & Percentage (\%) \\
\hline Very satisfied & 23 & 33.8 \\
\hline Satisfied & 7 & 10.3 \\
\hline Very good & 21 & 30.9 \\
\hline Good & 10 & 14.7 \\
\hline Average & 7 & 10.3 \\
\hline Total & 68 & 100 \\
\hline
\end{tabular}

The table above showed that, $33.8 \%$ felt very satisfied with the way their doctors attended to them, $10.3 \%$ felt satisfied with the way their doctors attended to them; $30.9 \%$ felt very good with the way their doctors attended to them, $14.7 \%$ felt good while $10.3 \%$ felt averaged. Thus, the average satisfaction patients got from their doctors was very satisfied with the highest frequency of 23.

Table10. Showing the overall level of satisfaction with the way patients were attended to.

\begin{tabular}{|c|c|c|}
\hline Item & Frequency & Percentage (\%) \\
\hline Satisfied & 29 & 42.6 \\
\hline Average & - & - \\
\hline
\end{tabular}


Comparative Study on the Performance of Health Workers in the Reduction of Patients Waiting Time in Public Hospitals in Yenagoa

\begin{tabular}{|c|c|c|}
\hline Not satisfied & 36 & 52.9 \\
\hline Applicable & 1 & 1.5 \\
\hline Total & 68 & 100 \\
\hline
\end{tabular}

From the table above, $42.6 \%$ of the patients said they were satisfied with the way they were attended at the hospital - Niger Delta University Teaching Hospital Okolobiri, with a frequency of 29; 52.9\% said they were not satisfied at all with the way they were attended to with a frequency of 36 . Thus, the average level of total satisfaction of the patients was that, they were not satisfied with the highest frequency of 36.

Table11. Showing the rating of the cleanliness and the comfort of the Outpatients Department (OPD) of the Hospital (NDTH-Okolobiri)

\begin{tabular}{|c|c|c|}
\hline Item & Frequency & Percentage (\%) \\
\hline Very poor (1) & 13 & 19.1 \\
\hline Poor (2) & 10 & 14.7 \\
\hline Fair (3) & 27 & 39.7 \\
\hline Good (4) & 12 & 17.6 \\
\hline Very good (5) & 6 & 8.8 \\
\hline Total & 68 & 100 \\
\hline
\end{tabular}

Based on the rating of the cleanliness and comfort of the OPD of NDTH-Okolobiri by the outpatients, the average rating with the highest frequency was fair with 39.7\%. Meaning that, the cleanliness and comfort of the $O P D$ of the hospital from the assessment of the outpatients was not too good or too bad.

\section{Comparative Analysis of the Patients' Waiting Time and their Satisfaction of the Three Hospitals}

\begin{tabular}{|c|c|c|c|c|c|c|}
\hline Hospitals & $\begin{array}{c}\text { Patients } \\
\text { average } \\
\text { waiting } \\
\text { time to } \\
\text { meet with } \\
\text { their } \\
\text { doctors } \\
\text { after arrival }\end{array}$ & $\begin{array}{c}\text { Average } \\
\text { amount of } \\
\text { time taken } \\
\text { by doctors to } \\
\text { attend to } \\
\text { their patients }\end{array}$ & $\begin{array}{c}\text { The average rate } \\
\text { of satisfaction } \\
\text { patients got } \\
\text { from meeting } \\
\text { with their } \\
\text { doctors } \\
\text { overall } \\
\text { satisfaction of } \\
\text { patients with the } \\
\text { way they were } \\
\text { attend to }\end{array}$ & $\begin{array}{c}\text { The average } \\
\text { cleanliness and } \\
\text { comfort of the } \\
\text { OPD of the } \\
\text { hospital }\end{array}$ & $\begin{array}{c}\text { The average } \\
\text { rating of the } \\
\text { receptionist as } \\
\text { regards to how } \\
\text { patients were } \\
\text { attended to }\end{array}$ \\
\hline FMC & $15-30 \mathrm{mins}$ & $30-1$ hour & Very good & Satisfied & Good & Very good \\
\hline DKMH & $15-30 \mathrm{mins}$ & $15-30 \mathrm{mins}$ & Very satisfied & Not satisfied & Fair & Very good \\
\hline NDTH & $15-30 \mathrm{mins}$ & $30-1$ hour & Very satisfied & satisfied & Fair & Very good. \\
\hline
\end{tabular}

\section{DisCUSSION AND SUMmaRY OF FINDINGS}

The study focused on a comparative assessment of the performance of health workers using patients waiting time as the yardstick to measure their performance. Based on the standards set by the Patients Charter of the United Kingdom (UK) government, which states that all patients must be seen within 30minutes of their appointment time. Thus, waiting time on this study was set within 30 minutes to measure the performance of the health workers of the three major public hospitals in Bayelsa state. From the findings, the three hospitals were able to meet with their outpatients within 30minutes on the average of their appointment time. This implies that, health workers in the three hospitals are performing well. However, the time doctors spent to meet with their patients differs in the three hospitals:

- Federal Medical centre (FMC) Yenagoa; spent 30 minutes -1 hour. Thus, the doctors are fairly efficient.
- Diete Koki Memorial Hospital (DKMH) Opolo, Yenagoa; spnet 15-30minutes. Thus, the doctors are very efficient.

- Niger Delta University Teaching Hospital (NDTH), Okolobiri; spent 30minutes-1hour. Thus, the doctors are fairly efficient

However, the study also looked at other areas to measure performance of the health workers of these three hospitals such as customers' or patients' satisfaction:

- The patients were satisfied with the way doctors attended to them in the three hospitals but DKMH and NDTH (very satisfied) did better than FMC (very good).

- The overall satisfaction of patients with the way they were attended to; patients were satisfied on the average with FMC and NDTH (satisfied) but patients were not satisfied with the way they were attended to in DKMH (not satisfied), which may be due to inadequate cordial relationship between 
the nurses/non-medical staff and the patients they attend to.

- The cleanliness and comfort of the OPD; FMC was good and DKMH and NDTH was fair on the average.

- The receptionists in the three hospitals did well in attending to patients as their ratings on the average were 'very good'.

\section{CONCLUSION}

One hundred (100) questionnaires were administered to each of the hospital titled "Performance of Health Workers in the Reduction of Patients' Waiting Time in Public Hospitals in Yenagoa". Sixty eight (68) questionnaires were filled and retrieved from FMC and NDTH while sixty six (66) were retrieved from DKMH. Frequency and simple percentage distribution methods of analyses were used to analyzed the data. Findings from the study revealed that, the performance of the health workers in the three hospitals -FMC, DKMH and NDTH all in Bayelsa State, using patients waiting time as a parameter as well as using Patients Charter of the United Kingdom (UK) government standards - which states that all patients must be seen within 30minutes of their appointment time. The study concluded that, all the three hospitals met the UK standards of seeing their patients within 30minutes after arrival on the average. Though, the amount of time doctors spent in meeting with their patients differed from hospital; FMC and NDTH spent 30minutes -1hour. Therefore, FMC and NDTH doctors are fairly efficient. However, DKMH doctors spent 15-30minutes hence, they are more efficient.

The cleanliness and comfort of the OPD from the findings, FMC is good but DKMH and NDTH is not too good or too bad.

The receptionists for all the three hospitals were very good with their performance from the rating of the patients.

\section{RECOMMENDATION}

From the findings, the researcher made the following recommendations:

- The doctors in FMC and NDTH should reduce the time spent in attending to a patient per time as recommended by the Patients Charter of the United Kingdom (UK) standards as the study revealed that doctors in FMC and NDTH spent 30-1hour on the average in attending to a patient compared to DKMH.
- DKMH, having met the standards as recommended by the Patients Charter of the United Kingdom (UK) by reducing patients' waiting time, yet about $52.9 \%$ of the patients interviewed were not satisfied with the way they were attended to. May be it is due to inadequate cordial relationship between the nurses/non-medical staff and the patients they attend to. So they should strengthen this area to make all the health services they rendered perfect.

- All the three hospitals especially DKMH and NDTH should put more efforts to improve on their OPD to put their patients at ease so as to make waiting enjoyable by providing TV, free WIFI and complimentary food and beverages such as snacks.

- Holistically, the study also observed that the three hospitals should increase their manpower.

- Suggestion from the patients indicated that, the OPD capacity be increase and the spoilt equipments such as toilets, chairs, fans, etc. should be repaired or replaced

- Patients waiting time should be communicated to them before hand so as to curtail their anxiety.

\section{REFERENCES}

[1] Ajayi IO, Olumide EA, Oyediran O (2005). Patient satisfaction with the services provided at a General Outpatients' Clinic, Ibadan, Oyo State, Nigeria. Afr. J. Med. Sci., 34(2):133-140.

[2] Baker DW, Stevens CD, Brook RH (1991). 'Patients who leave a public hospital emergency department without being seen by a physician: Causes and consequences', JAMA, 266: 1085-1090.

[3] Bamgboye E, Jarallah J (1994). Long waiting Outpatients: Target Audience for Health Education. Patient. Educ. Counsell., 23: 49-54

[4] Dos Santos L, Stewart G, Rosenberg N (1994). Paediatric emergency department walkouts. Ped. Emer. Care., 10: 76-78.

[5] Jawaid M, Ahmed N, Alam SN, Rizvi BH, Razzak HA (2009) Patients' experiences and satisfaction from a Surgical Outpatient department of a Tertiary Care Teaching Hospital. Pakistan. J. Med. Sci.,25(1):3; 439442.

[6] Kurata J, Nogawa A, Philips D, Hoffman S, Werblum M (1992). Patient and Provider satisfaction with medical care. J. Fam. Prac., 35: 176-179. 
Comparative Study on the Performance of Health Workers in the Reduction of Patients Waiting Time in Public Hospitals in Yenagoa

[7] Mackey TA, Cole FL (1997). Patient Waiting Time in Nursing Managed Clinic. The Int. J. Adv. Nur. Practice., 1 p. 1.

[8] Maitra A, Chikhani C (1992). Patient satisfaction in an Urban Accident and Emergency department. Br. J. Clin. Pract.,46(3):182-184.

[9] Net N, Chompikul J, Sermsri S. (2007). Patient satisfaction with health services in the Out Patient Department Clinic of Nangmamyen Community Hospital Sakeao Province, Thailand. J. Public Health. Devel., 5( 2): 33-42.

[10] Okotie OT, Patel N, Gonzalez CM (2008). The effect of Patient arrival time on the overall waiting time and utilization of Physician and examination room resources in the Out Patient Urologic Clinic. Advances in Urology do,10(1155): 507436.

[11] O'malley M, Fletcher S, Fletcher R, Earp J. (1993). Measuring Patient waiting time in a practice setting: A comparison of methods. J. Amb. Care. Manage., 6: 20-27.
[12] Pothier DD, Frosh A. (2006). Do Information sheets improve Patient Satisfaction in the Outpatient Department? Ann R Coll Surg Engl. 88(6):557-561.

[13] Prasanna KS, Bashith MA, Sucharitha S (2009). Consumer satisfaction about Hospital services: A study from the Outpatient department of a Private Medical College Hospital at Mangalore. Indian J. Comm. Med., 34( 2): 156-159.

[14] Roy PP (2002). Client satisfaction in Outpatient Medical Care services in Sampran Community Hospital, Thailand (MPHM Thesis in PHC Management) Nakhom Pathom:Fac of Graduate Studies, Mahidol University.

[15] Thatcher TD (2005). Outpatient waiting time in Jos University Teaching Hospital (JUTH). Highland. Med. Res. J., 3(1): 36-42.

[16] Thompson DA, Yarnold PR. (1995). Relating Patient satisfaction to waiting time perception and expectation: The disconfirmation paradigm. Acad. Emerg. Med., .2(12):1057-1062.

\section{Appendix}

\section{QUESTIONNAIRE}

Dear Respondent,

You are being invited to participate on a study titled; "A comparative study on the performance of healthcare providers in the reduction of patients waiting time in public hospitals in Yenagoa".

The survey is carried out to complete an article for writing for academic purposes, your participation in this study is entirely voluntary and you can withdraw at any time you wish. You are free to omit any question. The identity of individual respondent as well as respondent identifiable information will remain confidential; your response is completely anonymous.

Thank you for your time.

Please tick your response for each question and select only one option.

Demographics of the Respondent

1. Age

2. Sex

3. Occupation

4. Residential locality

5. Have you been to the hospital for treatment? If no

6. Did you take appointment or make an enquiry if the doctor you are coming to see is available before coming?

Yes [ ] No [ ]

If yes how was the appointment taken?

By person [ ] by phone [ ] not Applicable [ ]

7. How satisfied are you with the way the way your appointment was taken? Very satisfied [ ] very good [ ] good [ ] average [ ] poor [ ] very poor [ ]

8. How will you rate your reception staff and how you are attended to on this regard? Very satisfied [ ] very good [ ] good [ ] average [ ] poor [ ] very poor [ ]

9. How long did it take you to meet your doctor after arrival? $<15$ mins [ ]15-30mins [ ] 30-1hour [ ] 1hour and above [ ]

10. How satisfied are you with the rate at which you where attended to? Satisfied [ ] average [ ] not satisfied [ ] applicable [ ]

11. How would you rate the cleanliness and comfort of the hospital OPD you visited? 1 [ ] 2 [ ] 3 [ ] $45[$ [ ] 
Comparative Study on the Performance of Health Workers in the Reduction of Patients Waiting Time in Public Hospitals in Yenagoa

12. Any suggestion for improvement of the OPD and service rendered.

13. How satisfied is your meeting with your doctor? satisfied [ ] very good [ ] good [ ] average [ ]

14. How long did it take the doctor to attend to you?

Very satisfied [ ] [ ] 1hour and above [ ]

15-30mins [ ] 30-1hour

Citation: Diri, G.E. \& Eledo, B.O., "Comparative Study on the Performance of Health Workers in the Reduction of Patients Waiting Time in Public Hospitals in Yenagoa”, International Journal of Research Studies in Medical and Health Sciences. 2020; 5(8): 01-13.

Copyright: (C) 2020 Diri, G.E. \& Eledo, B.O., This is an open-access article distributed under the terms of the Creative Commons Attribution License, which permits unrestricted use, distribution, and reproduction in any medium, provided the original author and source are credited. 